\title{
A morphometric analysis of pedicles of lumbar vertebrae by using computed tomography scan
}

\section{Mansur DI ${ }^{1 D}$, Karki $\mathrm{S}^{2}$, Mehta DK ${ }^{3}$, Shrestha $\mathrm{P}^{3}$, Maskey $\mathrm{S}^{4}$}

'Dil Islam Mansur, Associate Professor, Department of Anatomy, Kathmandu University School of Medical Sciences, Dhulikhel, Nepal; ${ }^{2}$ Subindra Karki, Associate Professor, Department of Radio-Diagnosis, Dhulikhel Hospital / Kathmandu University Hospital, Dhulikhel, Nepal; ${ }^{3}$ Dilip Kumar Mehta; ${ }^{3}$ Pragya Shrestha, Assistant Professor; ${ }^{4}$ Sunima Maskey, Lecturer; Department of Anatomy, Kathmandu University School of Medical Sciences, Dhulikhel, Nepal.

\begin{abstract}
Background: The vertebral column is the central pillar of the body which has cervical, thoracic, lumbar, sacral and coccygeal parts. Out of these, the lumbar part is made up of five lumbar vertebrae which lies between the thoracic part above and the sacral part below.

Objectives: The study aimed to measure pedicle dimensions of lumbar vertebrae by using computed tomography scan. Methodology: This was a descriptive cross-sectional study which was conducted on 115 images of computed tomography scan which were available in the Department of Radio-diagnosis. Pedicle chord length, breadth and thickness of pedicle of lumbar vertebrae were measured in millimeter $(\mathrm{mm})$.

Results: The pedicle chord length and breadth progressively decrease from L1 to $L 5$ vertebral levels and pedicle thickness gradually increases from L1 to L5 vertebrae on both sides in both genders. The pedicle chord lengths were found significantly different whereas breadth and thickness were insignificantly different between males and females at all lumbar vertebral levels except at $\mathrm{L} 1$ for breadth.

Conclusions: The pedicle chord length and breadth gradually decreases whereas thickness increases from L1 to L5 vertebral levels amongst Nepalese population.
\end{abstract}

Key words: Age groups; Lumbar vertebrae; Pedicle screws.

\section{INTRODUCTION}

T There are five lumbar vertebrae present between the thoracic vertebrae and sacrum in the vertebral

\begin{tabular}{l}
\hline Access this article online \\
Website: www.jkmc.com.np \\
DOI: https://doi.org/10.3126/jkmc.v9i1.33547 \\
HOW TO CITE \\
MansurDI, KarkiS, Mehta DK, Shrestha P,MaskeyS.Amorphometric \\
analysis of pedicles of lumbar vertebrae by using computed \\
tomography scan. J Kathmandu Med Coll. 2020;9(1):49-55.
\end{tabular}

Address for correspondence

Dr. Dil Islam Mansur

Associate Professor, Department of Anatomy

Kathmandu University School of Medical Sciences

Dhulikhel, Nepal

E-mail: dilislam@kusms.edu.np

Contact: +9779861484747

Copyright $\odot 2020$ Journal of Kathmandu Medical College (JKMC)

ISSN: 2019-1785 (Print), 2091-1793 (Online)

(i) (3) This work is licensed under a Creative Commons Attribution-Non Commercial 4.0 International License. column. They are designated as L1 to L5 in craniocaudal direction. They help in the support of body weight and permit various movements. The pedicles of the lumbar vertebra are short and thick with flattened dorsal projections from the upper part of the body at the junction of its lateral and dorsal surfaces ${ }^{1}$.

The lumbar pedicles play an important role in the transfer of body weight from the neural arch to the anterior part of the vertebral column². An accurate knowledge of the lumbar pedicle dimensions has imperative implications for surgical interventions ${ }^{3}$. The majority of clinicians apply anatomical landmarks to guide pedicle screw placement in the lumbar spine ${ }^{4}$. In spite of recent techniques, the incidence of pedicle screw misplacement in the lumbar spine remains an important ${ }^{5}$. Still a study quoted that screw diameter more than $65 \%$ of the pedicle may damage its wall in $85 \%$ of cases $^{6}$.

Though the pedicle screw fixation has developed as a very successful method of spinal fixation ${ }^{7}$, it has disadvantages, such as mismatched size of screw and 
pedicle ${ }^{8}$. The knowledge of pedicle dimensions is crucial for the safe placement of pedicle screws. The data is not sufficiently available for Nepalese population. Thus, the present study was aimed to evaluate lumbar pedicle dimensions by using computed tomography (CT) scan images.

\section{METHODOLOGY}

A descriptive cross-sectional study was conducted in the Department of Anatomy and data was collected from the Department of Radio-Diagnosis, Dhulikhel Hospital/ Kathmandu University Hospital, Dhulikhel, Nepal by using images of CT scan. A total of 115 images of adult individuals (60 males and 55 females) were included during the period of six months (May-October 2019) for the study after receiving ethical approval from IRCKUSMS (Ref. no. 159/19). The images of individuals having normal spinal architecture without any obvious fracture and deformity of the vertebrae were included; and having history of spinal surgery, deformities and preexisting spinal pathology were excluded from the study. Pedicle chord length, breadth and thickness of pedicle of lumbar vertebrae were measured in millimeters. The pedicle dimensions were measured by lines drawn on the CT scan images using options provided in the Digital Imaging and Communications in Medicine software and the values were directly recorded from the monitor screen in millimeter $(\mathrm{mm})$. Pedicle chord length was measured along the long axis of the pedicle from the anterior cortex of the vertebral body to the posterior cortex of pedicle (Figure 1). Breadth of the pedicle was measured as the vertical diameter of the pedicle from the upper margin to lower margin of pedicle in the sagittal plane (Figure 2). Thickness of the pedicle was measured as the transverse diameter of the pedicle perpendicular to the long axis of the pedicle (Figure 3$)^{9}$.

All the scans available in the department were taken for the study. Data was collected and entered in Microsoft excel. Point estimate at $95 \%$ Confidence Interval was calculated along with frequency and proportion for binary data. The collected data was analyzed by using the Statistical Package for the Social Sciences version 16 (SPSS 16.0) for descriptive statistical analysis. P value was calculated to find the level of significance and $p$ value $<0.05$ was considered as significant.

\section{RESULTS}

Pedicle chord length: In males, the mean values for pedicle chord length was found maximum at L1
$(44.72 \pm 4.05 \mathrm{~mm})$ and minimum at $\mathrm{L} 5(42.32 \pm 3.78 \mathrm{~mm})$ on right side likewise on left side it was found maximum at L1 $(44.71 \pm 3.94 \mathrm{~mm})$ and minimum at L5 $(42.27 \pm 3.76$ $\mathrm{mm}$ ) as shown in table 1. In females, the mean value for pedicle chord length was found maximum at L1 $(41.60 \pm 3.28 \mathrm{~mm})$ and minimum at L5 $(38.29 \pm 3.20 \mathrm{~mm})$ on right side similarly on left side it was found maximum at L1 $(41.73 \pm 3.58 \mathrm{~mm})$ and minimum at L5 $(38.20 \pm 3.15$ $\mathrm{mm}$ ). Hence, it was found that the pedicle chord length was gradually decreasing from L1 to L5 on both sides in both genders as shown in table 1. It was also reported that the difference in measurements between right and left side was statistically insignificant in both genders except at L4 in males. There was a statistically significant difference between pedicle chord length of males and females at all lumbar vertebral level as shown in table 2 .

Breadth: The mean values for breadth of pedicle was found maximum at $L 1(14.28 \pm 1.63 \mathrm{~mm})$ and minimum at L5 $(10.60 \pm 2.05 \mathrm{~mm})$ on right side and on left side it was found maximum at L1 $(14.63 \pm 1.81 \mathrm{~mm})$ and minimum at L5 $(10.61 \pm 1.59 \mathrm{~mm})$ in males. Similarly in females, these values were found maximum at $L 1(13.92 \pm 1.93 \mathrm{~mm})$ and minimum at $L 5(10.73 \pm 1.59 \mathrm{~mm})$ on the right side. On the left side, it was found maximum at L1 $(13.94 \pm 1.88$ $\mathrm{mm})$ and minimum at $L 5(10.36 \pm 1.59 \mathrm{~mm})$. Hence, it was reported that the breadth was gradually decreasing from $\mathrm{L} 1$ to $\mathrm{L} 5$ on both sides in both genders as shown in table 1. The difference in breadth between right and left side was statistically insignificant in both genders except at L2 and L4 in males. There was statistically insignificant difference in breadth, between males and females at all lumbar vertebral level except at L1 as shown in table 2 .

Thickness: The mean values for thickness of pedicle was found maximum at $L 5(10.21 \pm 3.75 \mathrm{~mm})$ and minimum at L1 $(6.82 \pm 1.47 \mathrm{~mm})$ on right side whereas on left side it was found maximum at L5 $(10.45 \pm 3.79 \mathrm{~mm})$ and minimum at $L 1(6.70 \pm 1.84 \mathrm{~mm})$ in males. In females, these values were found maximum at $L 5(10.19 \pm 2.83 \mathrm{~mm})$ and minimum at L1 $(6.98 \pm 1.83 \mathrm{~mm})$ on right side. On left side it was found to be maximum at $L 5(10.09 \pm 2.81 \mathrm{~mm})$ and minimum at L1 $(6.84 \pm 1.43 \mathrm{~mm})$. Hence, it was observed that the pedicle thickness was gradually increasing from L1 to $L 5$ on both sides in both genders as shown in table 1. There was statistically insignificant difference between right and left side in both genders except at $L 4$ in males. There was statistically insignificant difference between males and females at all lumbar vertebral level as shown in table 2 . 
Table 1: Statistical analysis of right and left pedicles among both genders

\begin{tabular}{|c|c|c|c|c|c|c|c|}
\hline \multirow[b]{2}{*}{ Vertebrae } & \multirow[b]{2}{*}{$\begin{array}{l}\text { Parameters in } \\
\text { millimeter }(\mathrm{mm})\end{array}$} & \multicolumn{2}{|c|}{ Males } & \multicolumn{4}{|c|}{ Females } \\
\hline & & $\begin{array}{c}\text { Right } \\
\text { (mean } \pm S D)\end{array}$ & $\begin{array}{c}\text { Left } \\
\text { (mean } \pm S D)\end{array}$ & P-value & $\begin{array}{c}\text { Right } \\
\text { (mean } \pm S D)\end{array}$ & $\begin{array}{c}\text { Left } \\
\text { (mean } \pm S D)\end{array}$ & P-value \\
\hline \multirow{3}{*}{ L1 } & Chord length & $44.72 \pm 4.05$ & $44.71 \pm 3.94$ & 0.93 & $41.60 \pm 3.28$ & $41.73 \pm 3.58$ & 0.47 \\
\hline & Breadth & $14.28 \pm 1.63$ & $14.63 \pm 1.81$ & 0.06 & $13.92 \pm 1.93$ & $13.94 \pm 1.88$ & 0.90 \\
\hline & Thickness & $6.82 \pm 1.47$ & $6.70 \pm 1.84$ & 0.53 & $6.98 \pm 1.83$ & $6.84 \pm 1.43$ & 0.30 \\
\hline \multirow{3}{*}{ L2 } & Chord length & $44.58 \pm 4.04$ & $44.55 \pm 3.92$ & 0.58 & $41.03 \pm 3.40$ & $41.04 \pm 3.54$ & 0.93 \\
\hline & Breadth & $13.60 \pm 1.58$ & $13.99 \pm 1.84$ & 0.02 & $13.59 \pm 1.62$ & $13.45 \pm 1.71$ & 0.40 \\
\hline & Thickness & $7.21 \pm 1.28$ & $7.23 \pm 1.67$ & 0.91 & $7.04 \pm 1.24$ & $7.06 \pm 1.36$ & 0.74 \\
\hline \multirow{3}{*}{ L3 } & Chord length & $44.37 \pm 3.85$ & $44.30 \pm 3.72$ & 0.51 & $40.23 \pm 3.31$ & $40.17 \pm 3.25$ & 0.40 \\
\hline & Breadth & $13.30 \pm 1.89$ & $13.36 \pm 1.73$ & 0.70 & $13.05 \pm 2.25$ & $12.92 \pm 1.90$ & 0.45 \\
\hline & Thickness & $8.67 \pm 1.84$ & $8.56 \pm 1.82$ & 0.35 & $8.89 \pm 1.65$ & $8.72 \pm 1.68$ & 0.20 \\
\hline \multirow{4}{*}{ L4 } & Chord length & $43.46 \pm 3.78$ & $43.29 \pm 3.76$ & 0.03 & $39.15 \pm 3.17$ & $39.09 \pm 3.14$ & 0.29 \\
\hline & Breadth & $11.76 \pm 1.87$ & $12.25 \pm 1.91$ & 0.00 & $12.31 \pm 1.48$ & $12.08 \pm 1.57$ & 0.14 \\
\hline & Thickness & $9.61 \pm 2.23$ & $9.39 \pm 2.11$ & 0.05 & $9.49 \pm 1.98$ & $9.66 \pm 2.03$ & 0.13 \\
\hline & Chord length & $42.32 \pm 3.78$ & $42.27 \pm 3.76$ & 0.75 & $38.29 \pm 3.20$ & $38.20 \pm 3.15$ & 0.15 \\
\hline \multirow{2}{*}{ L5 } & Breadth & $10.60 \pm 2.05$ & $10.61 \pm 1.59$ & 0.96 & $10.73 \pm 1.59$ & $10.36 \pm 1.59$ & 0.07 \\
\hline & Thickness & $10.21 \pm 3.75$ & $10.45 \pm 3.79$ & 0.23 & $10.19 \pm 2.83$ & $10.09 \pm 2.81$ & 0.33 \\
\hline
\end{tabular}

Table 2: Statistical analysis of lumbar pedicles among males and females in millimeter ( $\mathrm{mm}$ )

\begin{tabular}{|c|c|c|c|c|}
\hline Vertebrae & Sex & Chord length (mean \pm SD) & Breadth (mean $\pm S D$ ) & Thickness (mean \pm SD) \\
\hline \multirow{3}{*}{ L1 } & Males & $44.72 \pm 4.05$ & $14.45 \pm 1.72$ & $7.02 \pm 1.58$ \\
\hline & Females & $41.60 \pm 3.28$ & $13.93 \pm 1.90$ & $7.02 \pm 1.60$ \\
\hline & P-value & $<0.001$ & 0.02 & 0.98 \\
\hline \multirow{3}{*}{ L2 } & Males & $44.58 \pm 4.04$ & $13.60 \pm 1.57$ & $7.22 \pm 1.48$ \\
\hline & Females & $41.03 \pm 3.40$ & $13.59 \pm 1.62$ & $7.05 \pm 1.30$ \\
\hline & P-value & $<0.001$ & 0.95 & 0.34 \\
\hline \multirow{3}{*}{ L3 } & Males & $44.37 \pm 3.85$ & $13.33 \pm 1.80$ & $8.61 \pm 1.82$ \\
\hline & Females & $40.23 \pm 3.31$ & $12.99 \pm 2.08$ & $8.80 \pm 1.66$ \\
\hline & P-value & $<0.001$ & 0.16 & 0.39 \\
\hline \multirow{3}{*}{ L4 } & Males & $43.29 \pm 3.76$ & $12.00 \pm 1.90$ & $9.50 \pm 2.16$ \\
\hline & Females & $39.09 \pm 3.14$ & $12.19 \pm 1.53$ & $9.57 \pm 2.00$ \\
\hline & P-value & $<0.001$ & 0.39 & 0.79 \\
\hline \multirow{3}{*}{ L5 } & Males & $42.32 \pm 3.78$ & $10.61 \pm 1.82$ & $10.33 \pm 3.76$ \\
\hline & Females & $38.29 \pm 3.20$ & $10.55 \pm 1.59$ & $10.14 \pm 2.81$ \\
\hline & P-value & $<0.001$ & 0.78 & 0.66 \\
\hline
\end{tabular}




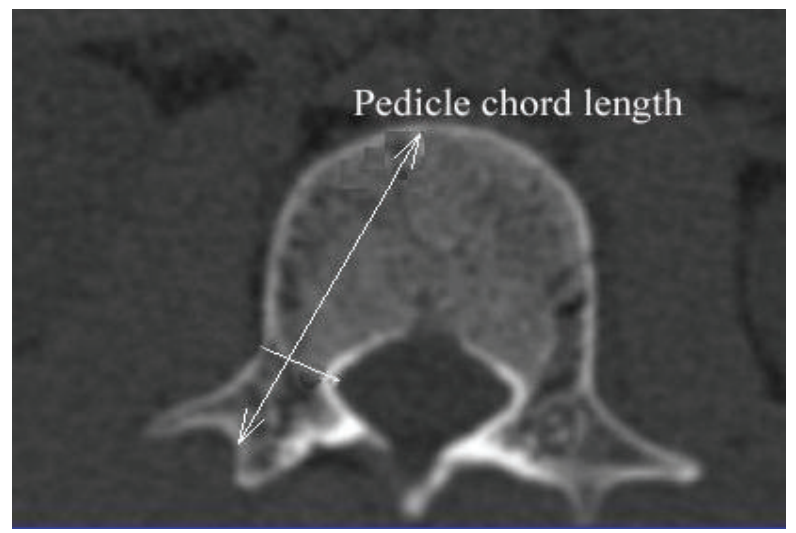

Figure 1: Showing measurement of pedicle chord length

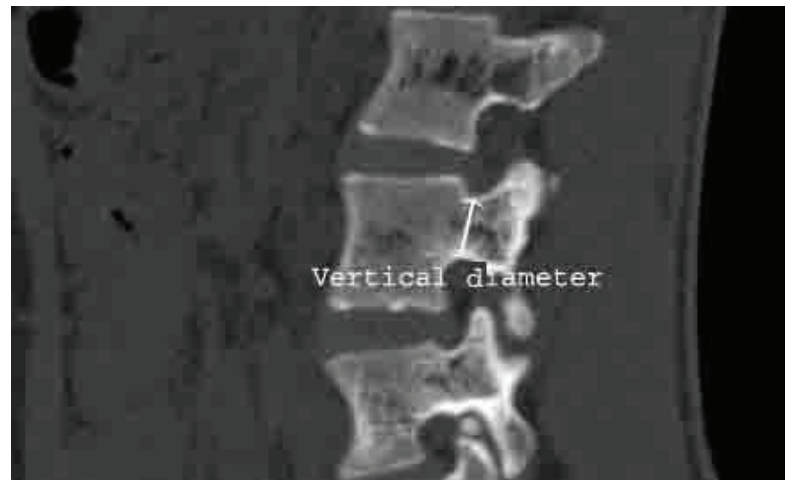

Figure 2: Showing measurement of pedicle breadth (vertical diameter)

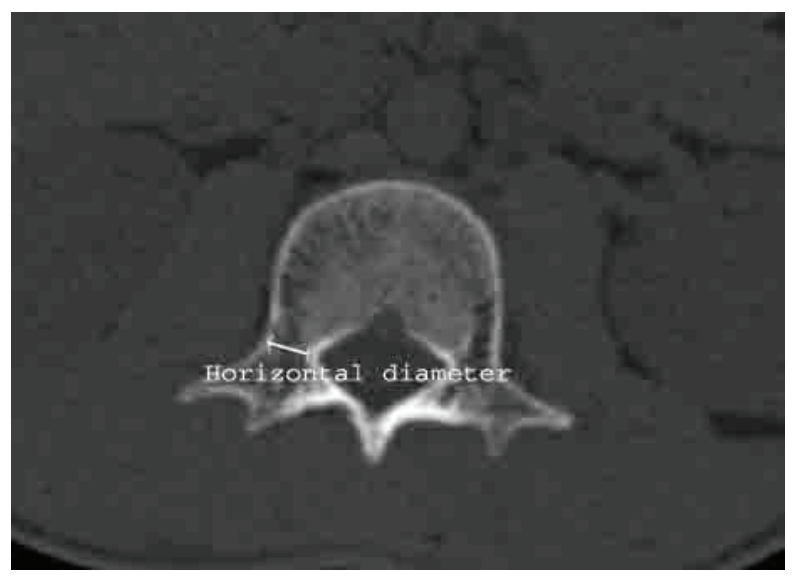

Figure 3: Showing measurement of pedicle thickness (horizontal diameter)

\section{DISCUSSION}

The lumbar region is often involved during accidents, degenerative disorders, inborn defects and metastasis. Therefore, artificial fixation may be needed for its activity to be regained. Any structural distortion of the pedicle may interfere the weight transmission mechanism and may compress the neural structures ${ }^{10}$. The pedicle of the vertebra has been used as a fixation site for vertebral implants. Pedicle screw fixation is a method of spine stabilization. It gives rigid, segmental stabilization and also allows maintenance of motion ${ }^{3}$. Therefore, having sharp knowledge the pedicle dimensions is noteworthy for performing a safe surgery ${ }^{11}$.

The pedicle chord length determines the safest length of any screw that can be used for pedicular fixation. It is important to prevent vertebral body perforation which may damage the important structures that lie anterior to the vertebral body ${ }^{12}$. A gradual decreasing pattern of pedicle chord length was found in the present study from L1 to L5 vertebral levels which are consistent with the studies in which it was observed that the pedicle chord length decreased gradually from $L 1$ to $L 5$ vertebrae in Egyptian $^{13}$ and Mexican populations ${ }^{14}$. This may be due to increasing weight bearing and associated increase in the size of the lumbar body from upper to lower lumbar vertebrae $^{15}$.

In contrast to the present study, a study reported the progressive increasing pattern of chord length from L1 to $L 5$ vertebrae ${ }^{16}$. The highest pedicle chord length value was found at L4 while the lowest value was recorded at L5 in western population in both genders ${ }^{17}$. A study of the Indian population found that the mean chord length value was the maximum at L2 and the minimum at L1 irrespective of gender ${ }^{18}$. But few studies reported the maximum chord length at $L 2^{10}$ and $L 4^{17}$. The variations in their results may be due to different ethnicities or regions.

In previous studies ${ }^{19,20}$, the chord lengths were found to have statistically insignificant differences between right and left pedicles in both genders which are in accordance with the present study except at L4 among males. The mean chord length in females was lower than in males at all levels ${ }^{10,12}$ which is consistent to the result of the present study. A study, among Iranian population, found the chord length values for males were higher than those of females at all vertebral levels ${ }^{21}$ which are also supported by the findings of the current study. In a study on Korean population, authors observed that the chord length had no significant difference between males and females ${ }^{22}$ whereas in the present study, there are significant gender differences. These differences may be due to many factors such as stature, body build or races ${ }^{10}$.

A study revealed that the mean pedicle breadth gradually decreases from L1 to L5 vertebrae ${ }^{23}$ which is consistent with the present study. However, a study 
amongst Saudi Arabian population had found a gradual increasing pattern of pedicle breadth from $L 1$ to $L 5$ in both genders ${ }^{8}$. A similar trend was also observed by authors who revealed the breadth of pedicles gradually increases from $L 1$ to $L 5^{11}$. These findings differ from the present study regarding breadth of the pedicles.

In contrast, a study reported, the pedicle breadth gradually increases from L1 to L3 vertebrae and slightly decreases at $L 4$ and $L 5$ vertebrae among adult Punjabi males ${ }^{24}$. Another study also reported that the breadth of the pedicle gradually increases from $L 1$ to $L 3$ vertebrae and again decreases at $L 4$ and $L 5^{25}$. Another study also observed that the breadth of pedicles decreases gradually from $L 1$ to $L 5$ except at $L 2$ where it increased (maximum at L2) ${ }^{23}$. A study in Nepal, observed that the breadth of pedicles increases from $L 1$ to $L 2$ and decreases from $L 2$ to $\mathrm{L}^{26}$. A study done in Mangalore, Karnataka, South India revealed that the breadth of both the pedicles increases from $L 1$ to $L 2$, then decreases from $L 2$ to $L 3$ and again increases from $L 3$ to $L 5^{27}$. But a study claimed that the breadth of pedicles decreased from $L 1$ to $L 5$ except at $L 2$ where it was maximum increased at $L 2^{23}$.

In a study on lumbar vertebrae, the mean pedicle breadth was noticed to have insignificant differences between right and left sides ${ }^{10}$ which is consistent with the present study except at L2 and L4. These results are also supported by a study in which the breadth was not found to have significant differences between right and left pedicles ${ }^{23}$ which is also consistent with this study. A study also observed that mean pedicle breadth values were found to have significant differences between males and females ${ }^{8}$ which is different to this study except at L1.

A gradual increasing pattern of pedicle thickness was found from L1 to L5 vertebrae in Egyptian ${ }^{13}$, South Indian $^{27}$, Taiwan ${ }^{28}$ and West Indian populations ${ }^{29}$. A similar trend was also recorded in Nepalese population. However, a study observed that the thickness of the pedicle decreases from $L 1$ to $L 5^{23}$. A study also reported that thickness of the pedicle gradually increased from $\mathrm{L} 1$ to $L 5$ vertebrae and thickness was nearly similar in $L 2$ and L3 vertebrae ${ }^{25}$. Another study reported that thickness of the pedicle gradually increases from L1 to L4 vertebrae and less at L5 vertebra among adult Punjabi males ${ }^{24}$.

Studies have also claimed that the thickness of right and left pedicles were almost same ${ }^{23,24}$ which is also supported by the results of the current study. A significant difference between the pedicle thickness of males and females were also reported in a study ${ }^{8}$ which is inconsistent with this study.

Many studies reported that the thickness of pedicles was progressively increasing from L1 to L4 and increased suddenly at L5. This showed that the thickness of the pedicles was gradually increasing towards the caudal vertebrae, which was seen in all the reported studies. The authors mentioned that, load has to pass through the pedicles against gravity at $L 5$ level $\mathrm{I}^{7,19,28}$. Therefore, the transfer of load from the body to the laminae in $L 5$ will be upwards against gravity, making L5 possess the strongest pedicles with maximum thickness ${ }^{3}$. In the present study also the thickness of pedicles is maximum at $L 5$ level on both sides and in both genders.

The vertebral pedicles are used for placement of screws through them for the management of the unstable lumbar spine and offer potential advantages over anterior instrumentation and hook rod devices ${ }^{30}$ and with the help of screws, various devices such as rods, plates or wires can be applied to spine for immobilization or fixation ${ }^{8}$. A misplaced or misdirected pedicle screw may cause injuries to the pedicle cortex, nerve root, facet joint and adjacent vital structures ${ }^{31,32}$.

The present study is done in a tertiary hospital which is located in the middle zone of Nepal, therefore the findings of this study can not be generalized. Limited sample size is also the limitations of the present study.

\section{CONCLUSION}

This study concludes that the mean values for pedicle chord length and breadth progressively decreases whereas thickness increases from L1 to $L 5$ vertebral levels amongst Nepalese population. Thus, the pedicle dimensions must be considered prior to the selection of a pedicle screw. It is also an essential to understand the pedicle dimensions for the development of techniques and devices for spinal instrumentation for safer pedicle screw placement. It may also generate the baseline data for this population which may help in further research activities.

\section{ACKNOWLEDGEMENTS}

Authors would like to thank and acknowledge Dr. Bishal Sah and all staff from the Department of Radio-diagnosis, Dhulikhel Hospital who helped in data collection.

Conflict of interest: None

Source(s) of support: None 


\section{REFERENCES}

1. Standring S. Gray's Anatomy, $40^{\text {th }}$ edition. Elsevier Limited: Churchill Livingstone; 2008. 723-4.

2. Pal GP, Routal RV. Transmission of weight through the lower thoracic and lumbar regions of the vertebral column in man. J Anat. 1987 Jun;152:93105. [PubMed | Full Text]

3. Philipose S, Kuriakose S, Viveka S, Kariappa M. Morphometric study of pedicles of lumbar vertebrae in Southern India. Journal of Evidence based Medicine and Healthcare. 2015 Sep 28;39(2):618291. [Full Text | DOI]

4. Robertson PA, Novotny JE, Grobler LJ, Agbai JU. Reliability of axial landmarks for pedicle screw placement in the lower lumbar spine. Spine. 1998 Jan1;23(1):60-6. [PubMed | DOI]

5. Laine T, Makitalo K, Schlenzka D, Tallroth K, Poussa $M$, Alho A. Accuracy of pedicle screw insertion: a prospective CT study in 30 low back patients. Eur Spine J. 1997 Dec;6(6):402-05. [PubMed | Full Text | DOI]

6. Sjotrom L, Jacobson $O$, Karstrom G, Pech $P$, Rauschning W. CT analysis of pedicle and screws tracts after implant removal in thoracolumbar fractures. J Spinal Disord. 1993 Jun;6(3):225-31. [PubMed |DOI]

7. Mitra SR, Datir SP, Jadhav SO. Morphometric study of lumbar pedicle in Indian population as related to pedicular screw fixation. Spine. 2002 Mar 1;27(5):453-9. [PubMed |DOI]

8. Amonoo-Kuofi HS. Age-related variations in the horizontal and vertical diameters of the pedicles of the lumbar spine. J Anat. 1995 Apr;186(2):321. [PubMed | Full Text]

9. Gulec A, Kaçıra BK, Kutahya $H$, Ozbiner $H$, Ozturk M, Solbas CS, et al. Morphometric analysis of the lumbar vertebrae in the Turkish population using three-dimensional computed tomography: correlation with sex, age, and height. Folia Morphol. 2017;76(3):433-9. [PubMed |DOI]

10. Chawla K, Sharma M, Abhaya A, Kochhar S. Morphometry of the lumbar pedicle in North West India. Eur J Anat. 2011;15(3):155-61. [Full Text]

11. Attar A, Ugur HC, Uz A, Tekdemir I, Egemen N, Genc Y. Lumbar pedicle: surgical anatomic evaluation and relationships. Eur Spine J. 2001 Feb;10:10-15. [PubMed |DOI]

12. Li B, Jiang B, Fu Z, Zhang D, Wang T. Accurate determination of isthmus of lumbar pedicle: a morphometric study using reformatted computed tomographic images. Spine. 2004 Nov 1;29(21):243844. [PebMed | DOI]
13. Maaly MA, Saad A, Houlel MEE. Morphological measurements of lumbar pedicles in Egyptian population using computerized tomography and cadaver direct caliber measurements. Egypt J Radiol Nucl Med. 2010 Dec;41(4):475-81. [Full Text | DOI]

14. Vega EU, Omana RE, Castro ODLG, Lopez SG. Morphometry of pedicle and vertebral body in a Mexican population by CT and Fluroscopy. Int J Morphol. 2009;27(4):1299-1303. [Full Text]

15. Azu OO, Komolafe OA, Ofusori DA, Ajayi SA, Naidu ECS, Abiodun AA. Morphometric study of lumbar vertebrae in adult South African subjects. Int J Morphol. 2016;34(4):1345-51. [Full Text | DOI]

16. Mistri S. Lower thoracic and lumbar pedicle morphometry using computerized tomography scan. Indian Journal of Basic and Applied Medical Research. 2016 Mar;5(2):236-48. [Full Text]

17. Olsewski JM, Simmons E, Kallen F, Mendel F, Severin C, Berens D. Morphometry of the lumbar spine: anatomical perspectives related to transpedicular fixation. J Bone Joint Surg. 1990 Apr;72(4):541-9. [PubMed | Full Text | DOI]

18. Acharya S, Dorje T, Srivastava A. Lower dorsal and lumbar pedicle morphometry in Indian population: a study of four hundred fifty vertebrae. Spine. 2010 May 1;35(10):E378-84. [PubMed | DOI]

19. Wolf A, Shoham M, Michael S, Moshe R. Morphometric study of the human lumbar spine for operation-workspace specifications. Spine. 2001 Nov 15;26(22):2472-7. [PubMed | DOI]

20. Chadha M, Balain B, Maini L, Dhaon BK. Pedicle morphology of the lower thoracic, lumbar, and S1 vertebrae: An Indian perspective. Spine. 2003 Apr 15;28(8):744-9. [PubMed]

21. Lotfinia I, Haddadi K, Sayyahmelli S. Computed tomographic evaluation of pedicle dimension and lumbar spinal canal. Neurosurg Quar. 2010 Sep;20(3):194-8. [DOI]

22. Kim NH, Lee HM, Chung IH, Kim HJ, Kim SJ. Morphometric study of the pedicle of thoracic and lumbar vertebrae in Koreans. Spine. 1994 Jun 15;19(12):1390-4. [PubMed | DOI]

23. Choubisa L, Babel H. Morphometric study of pedicles of dried adult human lumbar vertebrae in Udaipur zone. Int J Anat Res. 2018;6(3.3):5660-6. [Full Text | DOI]

24. Seema, Verma $P$, Singh M. Morphometric study of pedicles of the lumbar vertebrae in adult Punjabi males. Int J Anat Res. 2016;4(2):2401-4. [Full Text | DOI]

25. Wankhede HA, Jadhav SS, Katti AS, Herekar NG. Morphometric study of the pedicle of the dried adult 
human lumbar vertebrae. International Journal of Anatomy PhysiologyandBiochemistry.2014;1(1):1-5. [Full Text]

26. Marasini RP, Gautam P, Sherchan B, Gurung G, KC BR. A morphometric study of lumbar spine pedicles in Nepalese population. JCMS Nepal. 2014 OctDec;10(4):12-7. [Full Text | DOI]

27. Prakash, Prabhu LV, Vadgaonkar R, Pai MM, Ranade AV, Singh G. Morphometry of vertebral pedicles: A comprehensive anatomical study in the lumbar region. Int J Morphol. 2007 Jun; 25(2):393-406. [DOI]

28. Lien SB, Liou NH, Wu SS. Analysis of anatomic morphometry of the pedicles and the safe zone for through pedicle procedures in the thoracic and lumbar spine. Eur Spine J. 2007 Aug;16(8): 1215-22. [PubMed |Full Text | DOI]
29. Singel TC, Patel MM, Gohil DV. A study of width and height of lumbar Pedicles in Saurashtra region. J Anat Soc India. 2004;53(1):4-9. [Full Text]

30. Matsuzaki $H$, Tokuhashi $Y$, Matsumoto F, Hoshino $\mathrm{M}$, Kiuchi T, Toriyama S. Problems and solutions of pedicle screw plate fixation of lumbar spine. Spine. 1990 Nov;15(11):1159-65. [PubMed | DOI]

31. Weinstein JN, Spratt KF, Spengler D, Brick C, Reid S. Spinal pedicle fixation: Reliability and validity of roentgenogram-based assessment and surgical factors on successful screw placement. Spine. 1988 Sep;13(9):1012-8. [PubMed |DOI]

32. Misenhimer GR, Peek RD, Wiltse LL, Rothman SL, Widell EH Jr. Anatomic analysis of pedicle cortical and cancellous diameter as related to screw size. Spine. 1989 Apr;14(4):367-72. [PubMed | DOI] 